\title{
Research on the Relationship between Economic Growth and Environmental Technologies in China
}

\author{
Haibo Zhang \\ School of Management and Economics, Beijing institute of technology, Beijing, China
}

\begin{abstract}
Based on the time series data from 1990 to 2012,with the expanded IPAT model, the economic-environment coefficient (GT) was constructed to measure the impact of economic growth on the environmental technologies. The results showed that there was a diminishing trend of the impact in the period of 1990 -1998 except the year of 1996, meaning the coordinated development between economic growth and environment technologies. In order to further analyze the measures and methods of energy saving and emission reduction, DEA model was using for the calculation of input redundancy and output deficit value. The results revealed that the coal consumption keeps Pareto optimal all the time. The emission of pollution decreased and the employment rate increased gradually. The input redundancy decreased to efficiency in the second and third industries.
\end{abstract}

Keywords. Environmental technologies, economic growth; IPAT model; DEA model

\section{Introduction}

Since reform and opening up, with rapid economic development, the GDP ratio of China to the whole world rises to $15 \%$ from 5\% [1]. Along with rapid economic growth, ecological environment is continuing deterioration and energy consumption is too excessive. China became the country owing the largest energy consumption, exceeding America in 2010. The ratio of Chinese energy consumption to the one of the whole world was one fifth, meaning that energy consumption was significant to the rapid economic development. With the way of extensive economic development, it is difficult for China to realize the goal of constructing one country which is resource saving and environment friendly. Therefore research on the intrinsic relationship between economic growth and energy environment is helpful to safeguard energy security and rapid economic growth, and promote the coordinated development among energy, economy and environment.

\section{Literature review}

Research on the relationship between economic growth and environment has been concerned by scholars in recent years. According to the empirical data, Grossman and Krueger (1991) [2] proposed the hypothesis of inverted U type relationship between the pollution and income for the first time. The hypothesis was that in the early stages of economic development, per capita income was negatively related to environmental quality, and positively when economy beyond the critical value. Bruce (2004), Dinda (2004) [3,4] and other scholars had done theoretical and empirical studies on EKC. Based on Chinese input-output table, Garbaccio,R.F (1999) [5] analyzed the effect on energy consumption reduction from technology progress and structural change. The results showed that sectional technology progress 
reduced the energy output ratio, that structural change increased energy consumption, and that the import of energy intensive products lowered the energy intensity from 1987 to 1992. Hannesson,R. (2002) [6] studied the relationship between the growth rate of energy utilization and the growth rate of economy, by dividing 1950-1997 into 5 time periods which were low oil price period, the first energy crisis, high oil price period, 1974-1986 and oil prices falling back period. The results showed that after the first energy crisis, their relationship became weak. But it became strong again after 1986. The energy utilization rate is lower than the GDP growth rate in rich countries, with the contrary situation in poor countries.

With Environmental Sustainability Index (ESI), Hyun-Hoon Lee $(2011,2012)$ et al $[7,8]$ done regression analysis, concluding 2 pollution indexes which were air pollution and water pollution, and 9 kinds of efficiency index, to research the relationship between environmental stability and income. The results showed that GDP per capital had positive relationship with environmental stability index and pollution index, and negative relationship with eco-efficiency index. Through nonlinear STR model, Jinwen Zhao and Jitao Fan (2007) [9] studied the intrinsic structure relations between energy consumption and economic growth in China, and found that the effect characteristics of economic growth on energy consumption were nonlinear, non-symmetry and phase. By provincial panel data during 1991 and 2006, Shuai Shao (2008) [10] analyzed the correlation and transmission mechanism between energy development and economic growth in the western region, finding that energy development had negative correlation with economic growth. Based on decoupling theory model, Chongmei Wang (2010) [11] found that economic growth and energy consumption were relative decoupling after 2000 in China, considering historical data from 1990 to 2007 as sample. According to the index of energy consumption per unit output, Yanxu Wei et al. (2011) [12] compared two stages which were one from 1953 to 1977 and one from 1978 to 2009, to study the relationship between energy consumption and economic growth with the help of IPAT equation. The conclusions were that in the former 30 years, the per capita energy consumption and per capita GDP were synchronous growth, meaning economic growth dependence on energy consumption. But in the later 30 years, along with the growth of per capita GDP, per capita energy consumption increased volatility, and more depended on technological progress, with less dependence on energy consumption. Adopting the modified model, Peng Li (2013) [13] empirically test the interdependence between energy consumption and economic growth, selecting the panel data from 1995 to 2008. The result was that economic growth was the one-way Grainger reason to energy consumption.

Based on the above research results, according to the actual situation of China and data, this paper studied the impact of economic growth on the environment, with the IPAT and expanded model. And energy economic efficiency change over the years, the input redundancy of the output and output deficit situation were analyzed by DEA model to reflect the actual efficiency of economy growth and implementation effect of energy-saving emission reduction policies. Those empirical analysis which were effect of environment on economy growth and environment efficiency, were used to provide a theoretical basis for energy saving and emission reduction policies.

\section{Assessment on the impact of economic growth on energy environment}

\subsection{Establishment of model}

70's last century, Ehrlich and Holden [14,15] proposed IPAT model to measure impact of economic activities on environment, to find out the main driving force of human activities to environment. All the factors are classified into three categories in the model, which are population, affluence and technology. The model can be written as

$$
I=P \times A \times T
$$

Where I is environmental impact index, meaning impact to represent energy consumption, or waste emission and so on, $\mathrm{P}$ being population to be represented by the total population at the end of the year, A being affluence, to be represented by per capita GDP, that is $A=G D P / P$, T being technology, to be represented by the environmental impact of per unit GDP, that is T=I/GDP [16], G means GDP, then the formula (1) can be transformed into 


$$
I=G \times T
$$

Assuming that the GDP of base year is $\mathrm{G}_{0}$, with an average annual growth rate of $\mathrm{g}$, the technical level of the base year denoted as $\mathrm{T}_{0}$, with an average annual growth rate of $\mathrm{t}$, then the $G_{n}, T_{n}$ and $I_{n}$ can be written as

$$
\begin{gathered}
G_{n}=G_{0} \times(1+g)^{n} \\
T_{n}=T_{0} \times(1-t)^{n} \\
I_{n}=G_{n} \times T_{n}
\end{gathered}
$$

The nth environmental impact can be obtained by bring (3) and (4) into (5).

$$
I_{n}=G_{0} \times T_{0} \times(1+g)^{n} \times(1-t)^{n}=G_{0} \times T_{0} \times(1+g-t-g t)^{n}
$$

In the formula (6),

(1) if $g-t>g t$, then the environmental impact increases year by year.

(2) if $g-t=g t$, then the environmental impact stays stable.

(3) if $g-t<g t$, then the environmental impact decreases year by year.

Economic environment coefficient GT is defined as index to measure the environmental impact.

$$
G T=g-t-g t
$$

If GT $>0$, then the environmental impact is larger than last year. If $\mathrm{GT}=0$, then the environmental impact is the same with last year. If $\mathrm{GT}<0$, then the environmental impact is smaller than last year.

\subsection{The empirical analysis}

In the paper, energy consumption is selected as the substitution variable to environmental impact I, $g$ being GDP added value. In order to eliminate the inflation factor, data are parity modified based on the price of 1980 as base one. The falling rate of energy consumption is represented by t. All data come from China Statistical Yearbook 1991-2012. The GT in every year is shown in Figure 1, by formula (7).

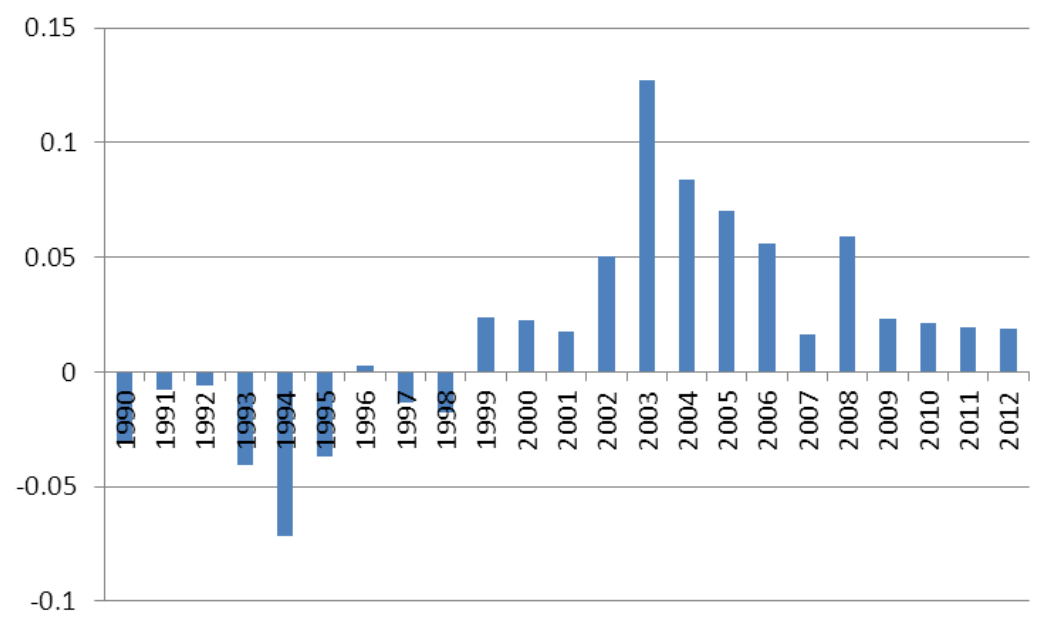

Fig. 1. Values of GT from 1990 to 2012.

From Figure 1, it can be seen that GT is fluctuant from 1990 to 2001. Except for 1994, the fluctuation values maintained in the vicinity of $-0.05-0.05$, with the good overall trend. The GT values were negative from 1990 to 1998 , but a few years, meaning that the impact effect of economic growth on the environment was declining, and that economy and environment were coordinated development. The values turned to be positive after 1998, but relatively small, meaning that economic growth led to the deterioration of the environment, but the deterioration degree was small. Since 2001, the damage degree increased, and to the maximum 0.127 in 2003. In the following years, the GT values 
decreased. The minimum 0.0163 appeared in 2007. After a small rise in 2008, the values stayed relatively stable fluctuation.

In 1998, China suffered severe flooding. At the same time, the international economic situation also had great changes, including that severe financial crisis took place in Southeast Asia, that the government changed moderately tight economic policies, into expansion ones of domestic demand, to stimulate economic growth, and that $70 \%$ of billions of treasury bonds was used in infrastructure construction with the positive fiscal polies. So GT turned into positive since 1998, and be the maximum in 2003. Environment deterioration prompted government to increase the energy-saving emission reduction efforts and to increase investment in science and technology. The effect was remarkable, so GT began to decline after 2003. While the international financial crisis in 2008 led the government to increase national expansion of infrastructure construction, therefor GT rebound because of reduced protection on the environment.

Based on the growth rate in every year, the average growth rate of GDP calculated is 0.1012 from 1990-2011, energy consumption decline rate 0.0889 , and total GT 0.01681 . The results showed that due to the national energy-saving emission reduction policies, economic growth can basically maintain coordinated development with environment. Then on the basis, DEA model can be applied to evaluate the redundant and deficit to further analyze the measure and methods of energy-saving emission reduction.

\section{DEA evaluation of economic growth and energy environment}

\subsection{DEA model}

In 1978, Data envelopment analysis (DEA) was proposed by A.Charnes, W.W.Cooper and E.Rhodes to evaluate the relative effectiveness among departments [17]. Its essence is a kind of method to measure the relative efficiency of decision-making units, with the same types of inputs and outputs, to decide whether they are located in the production frontier of production possibility set [18].

Assuming that there are $\mathrm{n} D M U_{j}$ in DEA model, which own the $m$ kinds of inputs $X_{j}$ and $s$ kinds of outputs $Y_{j}$, then input index vector $X_{j}=x_{1 j}, x_{2 j}, \cdots, x_{m j}{ }^{T}>0$ and output vector $Y_{j}=y_{1 j}, y_{2 j}, \cdots, y_{s j}{ }^{T}>0$ represent the input and output of $D M U_{j}, j=1,2, \cdots, n$. Then the validity of scale and technology of $D M U_{j_{0}}$ can be circulated by mathematical programming as

$$
\begin{array}{r}
\min \left[\theta-\varepsilon\left(e^{\hat{T}} s_{r}^{-}+e^{T} s_{p}^{+}\right)\right] \\
\left(D_{C^{2} R}^{T}\right)\left\{\begin{array}{l}
\sum_{j=1}^{n} X_{j} \lambda_{j}+S^{-}=\theta X_{0} \\
\sum_{j=1}^{n} Y_{j} \lambda_{j}-S^{+}=Y_{0} \\
\lambda_{j} \geq 0, j=1,2, \cdots, n \\
S^{-} \geq 0, S^{+} \geq 0
\end{array}\right.
\end{array}
$$

$\theta$ in formula(8) represents relative efficiency of $D M U j_{0}$, also called efficiency evaluation index. $\varepsilon=10^{-6} . \lambda_{j}$ is the combination ratio of the i DMU, with the restructured effective DMU combination compared to $D M U_{j_{0}} . S^{-}$and $S^{+}$are slack variables. $S^{-}$is vector of $m$ dimensions, $S^{-}=\left(s_{1}^{-}, s_{2}^{-}, \cdots, s_{r}^{-}\right)^{T}$, while $S^{+}$is vector of s dimensions, $S^{+}=\left(s_{1}^{+}, s_{2}^{+}, \cdots, s_{p}^{+}\right)^{T}$. 
$k=\sum_{j=1}^{n} \lambda_{j}$. When $k=1$, the validity of scale of $D M U_{j_{0}}$ is invariant. When $k<1$, the validity of scale of $D M U_{j_{0}}$ is increasing. When $k>1$, the validity of scale of $D M U_{j_{0}}$ is decreasing.

If and only if $\theta=1$ and $S^{-}=S^{+}=0, D M U_{j_{0}}$ can be called $D E A$ effective, reaching the Pareto optimal state. On the contrary, $D M U_{j_{0}}$ can be called $D E A$ weak effective or $D E A$ non-effective. If $D M U$ is not $D E A$ effective, then the original input vector and output vector can be adjusted to make it $D E A$ effective [19].

The point after adjusted is the projection of decision-making unit in the production frontier. Projection formula can be written as

$$
\left\{\begin{array}{c}
\hat{X}_{0}=\theta^{0} X_{0}-S^{-} \\
\hat{Y}_{0}=Y_{0}+S^{+}
\end{array}\right.
$$

\subsection{The empirical analysis}

According to the study results from Boqiang Lin [20, 21], Shaozhou Qi [22], Qiang He [23] and Angang Hu [24], in the selection of indicators, sulfur dioxide emission, coal consumption and population index are selected as input indicators, while the added value of the second industry, the added value of the third industry and GDP as output indicators [25]. The data come from China Statistical Yearbook, and the sample period is 1990-2012. The results calculated are shown in Tab.2.

Table 2. The results of DEA model.

\begin{tabular}{|c|c|c|c|c|c|c|c|}
\hline & \multirow{2}{*}{$\begin{array}{c}\text { Energy } \\
\text { DMU } \\
\text { efonomic } \\
\text { effiency } \\
\text { value }\end{array}$} & $\begin{array}{c}\text { Sulfur } \\
\text { dioxide }\end{array}$ & Population & $\begin{array}{c}\text { Coal } \\
\text { consumption }\end{array}$ & GDP & $\begin{array}{c}\text { Output } \\
\text { value of } \\
\text { the second } \\
\text { industry }\end{array}$ & $\begin{array}{c}\text { added } \\
\text { value of } \\
\text { the third } \\
\text { industry }\end{array}$ \\
\hline 1990 & 0.314 & 250 & 26209 & 0 & 0 & 574 & 2207 \\
\hline 1991 & 0.331 & 295 & 26791 & 0 & 0 & 445 & 2137 \\
\hline 1992 & 0.37 & 331 & 28715 & 0 & 0 & 204 & 1771 \\
\hline 1993 & 0.414 & 267 & 20273 & 0 & 0 & 0 & 1840 \\
\hline 1994 & 0.466 & 36 & 1355 & 0 & 465 & 0 & 2234 \\
\hline 1995 & 0.507 & 56 & 0 & 0 & 1097 & 0 & 1935 \\
\hline 1996 & 0.536 & 20 & 0 & 0 & 1459 & 0 & 2116 \\
\hline 1997 & 0.628 & 0 & 266 & 0 & 1497 & 0 & 2122 \\
\hline 1998 & 0.719 & 270 & 6015 & 0 & 812 & 0 & 1560 \\
\hline 1999 & 0.768 & 77 & 6778 & 0 & 597 & 0 & 1174 \\
\hline 2000 & 0.761 & 184 & 6486 & 0 & 750 & 0 & 973 \\
\hline 2001 & 0.812 & 117 & 5643 & 0 & 260 & 0 & 407 \\
\hline 2002 & 0.901 & 139 & 0 & 0 & 287 & 42 & 305 \\
\hline 2003 & 0.862 & 149 & 0 & 0 & 1698 & 99 & 0 \\
\hline 2004 & 0.841 & 162 & 0 & 0 & 2610 & 169 & 0 \\
\hline 2005 & 0.845 & 371 & 0 & 0 & 4030 & 0 & 326 \\
\hline 2006 & 0.876 & 334 & 0 & 0 & 1530 & 0 & 426 \\
\hline 2007 & 0.894 & 187 & 0 & 0 & 3318 & 41 & 0 \\
\hline 2008 & 0.901 & 175 & 0 & 0 & 1248 & 86 & 0 \\
\hline 2009 & 0.923 & 164 & 0 & 0 & 1101 & 75 & 0 \\
\hline 2010 & 0.945 & 152 & 0 & 0 & 1098 & 69 & 0 \\
\hline 2011 & 0.951 & 148 & 0 & 0 & 1065 & 61 & 0 \\
\hline 2012 & 0.968 & 132 & 0 & 0 & 1048 & 73 & 0 \\
\hline
\end{tabular}


As can be seen from Tab.2, energy input-output efficiency increased year by year, showing that the energy technology was in improving efficiency. Since 2000, the efficiency had been maintained at above 0.9. The decline in 2003 was due to the energy waste and one-sided pursuit of economic interests. Compared with the GT in Fig.1, GT in 2003 reached the highest level since 1990, showing that the environment indeed was destroyed. Through adjustment in several years, especially for the eleventh five-year plan proposed, the efficiency value was obviously increased and reaching Pareto optimality in 2008.

From the input perspective, the utilization efficiency of coal consumption was higher than the others in China. However there was no a decreasing trend of the sulfur dioxide produced by coal. The next step for China is to do more efforts on the treatment of waste gas, by more intensive rectification, to promote the coordinated development of economy and environment. From the output perspective, with the open market, cost could be reduced the most degree, to increase profit and effectively use the input. But due to the non-coordinated development between environment and economy, it needed great efforts to clean up the environment. As for output index, the second industry was always located in output efficiency. Owing the perfection of market economy and economic crisis diffusion in 2008, output redundancy of the third industry was on the decline, to produce fully effective in recent years.

As to input of population, there were two stages of population redundancy.

One was the period from 1990 to 1994, which was a crucial transition for China from planned economy to market economy. Under the planned economy, the enthusiasm was not high, with not guaranteed production efficiency, but also great waste of personnel was caused. The reason was that creativity was severely inhibited because of guiding plan. In that condition, the employees of state-owned enterprises formed a fixed and limited mode of thinking, because production and sales were planned by state-owned enterprises just following national mandatory, with marketing of high security from national plan. In the change to the market, state-owned enterprises were changed into company with state-owned shares as the leading, instead of contract system from 1994. With the changed policies, the population redundancy immediately dropped to one fifteen of the original, with remarkable results, in 1994.

The other one was period from 1997-2001, which was Asian financial crisis. Owing that the time of the crisis was June 1997, the employment had been impacted less. The following years were far-reaching ones by financial crisis. With effective regulatory policies of Chinese government, the population redundant was back to effective in 2002 .

\section{Conclusion}

Based on the former research results, considering Chinese situation and data obtained, IPAT model was introduced to this paper, with economic environment coefficient (GT) as indicator to measure environmental impact. The results showed that the environment impact of economic growth showed decreasing trend from 1990 to 1998 except for a few years, with coordinated development of economy and environment. After 1998, economic growth led to the deterioration of the environment, with small degree. Since 2001, the deterioration increased, reaching the maximum value in 2003. The deterioration of environment improved after a small peak in 2008. In order to further analyze the measures and methods of energy saving and emission reduction, DEA model was applied to evaluate the redundant and deficit. The DEA results showed that from the input, the coal consumption was always in Pareto efficient stage, with gradually decreased sulfur dioxide. The employment rate increased and was Pareto efficiency from 2002 to 2009. From the output, output gradually become more effective, along with the second industry in effective and the third industry with declined redundancy. Overall, energy-saving and emission reduction policies are moderate intensity, with reasonable implementation. The results achieved initial effective. Economic growth can basically maintain the stable and coordinated development with environment. 


\section{References}

1. Research group of the State Council Development Research Center, Yutai Zhang, Shijin Liu, et al. Study on country account of carbon dioxide emissions: governance framework to climate change and economic growth of green [J]. Economy Research, 2011 (2).(In Chinese)

2. Grossman G M, Krueger A B. Environmental impacts of a north american free trade agreement [J]. National Bureau of Economic Research Working Paper Series, 1991, No. 3914.

3. Dinda S. Environmental Kuznets Curve hypothesis: a survey [J]. Ecological Economics, 2004, 49(4):431-455.

4. Yandle B, Bhattarai M, and Vijayaraghavan M. Environmental Kuznets curves: a review of findings, methods, and policy implications [J]. Research study, 2004, 2:1-16.

5. Garbaccio R F, Ho M S, Jorgenson D W. Why has the energy-output ratio fallen in China? [J]. The Energy Journal, 1999:63-91.

6. Hannesson R. Energy use and GDP growth, 1950-97[J]. OPEC review, 2002, 26(3):215-233.

7. Lee H, Chung R K, Koo C M. The relationship between economic growth and environmental sustainability [J]. Research in Economics, 2011, 4(65):353-364.

8. Zhan S F, Zhang X C, Ma C, et al. Dynamic modelling for ecological and economic sustainability in a rapid urbanizing region [J]. Procedia Environmental Sciences, 2012, 13(0):242-251.

9. Jinwen Zhao, Jitao Fan. Empirical Research on inherent relationship between economic growth and energy consumption [J]. Economy Research, 2007 (08): 31-42. (In Chinese)

10. Shuai Shao, ZhongYing Qi. The western region's energy development and economic growth -- Empirical analysis based on "resource curse" hypothesis [J]. Economy Research, 2008 (4): 147-160. (In Chinese)

11. Chongmei Wang. decoupling analysis on Chinese economic growth and energy consumption[J]. China Population, Resources and Environment, 2010,20 (003): 35-37. (In Chinese)

12. Yanxu Wei, Gennian Sun, Jing Li. Based on technological progress Energy consumption and economic growth in China: compare the two 30 years [J]. Resources science, 2011, 33 (7): 1338-1345. (In Chinese)

13. Peng Li. Economic growth and energy consumption in China -- An Empirical Analysis Based on dynamic panel data [J]. Economic management, 2013 (1): 1-10. (In Chinese)

14. Ehrlich P, Holden J. One-dimensional economy [J]. The Bulletin of the Atomic Scientists, 1972,28(5):16-27.

15. Ehrlich P, Holden J. Impact of population growth [J]. Science, 1971,171:1212-1217.

16. Yu Dai, Yiwen Liu. An Empirical Study on city cluster in Chang Zhu Tan of economic growth and energy consumption Based on The IPAT model [J]. Mathematics economics, 2009, v.26 (02): 65-71. (In Chinese)

17. Quanling Wei. The DEA method of evaluation the relative effectiveness: operations research new field [M]. Renmin University of China press, 1988 (In Chinese)

18. Jun Chen, Jinhua Cheng. Efficiency evaluation of Chinese non-renewable energy production: the empirical research based on data envelopment analysis method [J]. Economic review, 2007 (05): 65-71. (In Chinese)

19. Lixin Xu, Wang Jin Shi. Based on two stage of DEA China's real estate Corporation business analysis [J]. Journal of University of Electronic Science and Technology (SOCIAL SCIENCE EDITION), 2013 (1). (In Chinese)

20. Boqiang Lin, Weixian Wei, Pidong Li. China long-term coal demand: effect and policy choice [J]. economic research, 2007,2:48-58. (In Chinese)

21. Boqiang Lin. The econometric analysis on Chinese energy demand [J]. Statistical research, 2001 (10): 34-39. (In Chinese)

22. Shaozhou Qi, Bo Yun, Kai Li. Research on convergence and mechanism analysis on Chinese economic growth and energy consumption [J]. Economy research 2009 (04): 56-64. (In Chinese) 
23. Qiang He, Guangming Lv. Analysis on the effect on ecological environmental based on IPAT model -- a case study of Beijing [J]. Journal of Central University of Finance and Economics based on, 2008 (12): 83-88. (In Chinese)

24. Angang Hu, Jinghai,Zheng Yuning Gao et al. Ranked the provincial technical efficiency considering environmental factors (1999 - 2005) [J]. Economics (Ji Kan), 2008 (3): 933-960. (In Chinese)

25. Dingtao Zhao, Huiping Dong. Analysis on technical efficiency and factors of regional tourism industry-- empirical research Based on two stage DEA-PCR model [J]. Journal of University of Electronic Science and Technology (SOCIAL SCIENCE EDITION), 2012 (6): 51-56. (In Chinese) 